\title{
Influence of Physical Dimension and Morphological-Dependent Antibacterial Characteristics of ZnO Nanoparticles Coated on Orthodontic NiTi Wires
}

\author{
Mona Gholami $\mathbb{D}^{1},{ }^{1}$ Mahdiyeh Esmaeilzadeh ${ }^{(\mathbb{D}},{ }^{2}$ Zahra Kachoei, ${ }^{3}$ Mojgan Kachoei $\mathbb{D}^{1,4}$ \\ and Baharak Divband ${ }^{5,6}$
}

${ }^{1}$ Department of Orthodontics, Faculty of Dentistry, Tabriz University of Medical Sciences, Tabriz, Iran

${ }^{2}$ Student Research Committee, Faculty of Dentistry, Tabriz University of Medical Sciences, Tabriz, Iran

${ }^{3}$ Polymer Division, Chemistry Department, School of Science, University of Tehran, Tehran, Iran

${ }^{4}$ Dental and Periodontal Research Center, Faculty of Dentistry, Tabriz University of Medical Sciences, Tabriz, Iran

${ }^{5}$ Department of Inorganic Chemistry, Faculty of Chemistry, University of Tabriz, Tabriz, Iran

${ }^{6}$ Dental and Periodontal Research Center, Tabriz University of Medical Sciences, Tabriz, Iran

Correspondence should be addressed to Mojgan Kachoei; drkachoei@gmail.com and Baharak Divband; divband@tabrizu.ac.ir

Mona Gholami and Mahdiyeh Esmaeilzadeh contributed equally to this work.

Received 12 June 2021; Revised 11 September 2021; Accepted 16 September 2021; Published 14 October 2021

Academic Editor: Saber Khazaei

Copyright (c) 2021 Mona Gholami et al. This is an open access article distributed under the Creative Commons Attribution License, which permits unrestricted use, distribution, and reproduction in any medium, provided the original work is properly cited.

\begin{abstract}
White spot lesions (WSLs) are one of the adverse effects of fixed orthodontic treatments. They are the primary sign of caries, which means inhibiting this process by antibacterial agents will reverse the procedure. The current study tested the surface modification of nickel-titanium (NiTi) wires with $\mathrm{ZnO}$ nanoparticles (NPs), as antimicrobial agents. As the morphology of $\mathrm{NPs}$ is one of the most critical factors for their properties, the antibacterial properties of different morphologies of $\mathrm{ZnO}$ nanostructures coated on the NiTi wire were investigated. For the preparation of $\mathrm{ZnO}$ nanostructures, five coating methods, including chemical vapor deposition (CVD), chemical precipitation method, polymer composite coating, sol-gel synthesis, and electrospinning process, were used. The antibacterial activity of NPs was assessed against Streptococcus mutans by the colony counting method. The obtained results showed that all the samples had antibacterial effects. The antibacterial properties of $\mathrm{ZnO}$ NPs were significantly improved when the specific surface area of particles increased, by the $\mathrm{ZnO}$ nanocrystals prepared via the CVD coating method.
\end{abstract}

\section{Introduction}

Orthodontic treatment, bonding brackets, and engaging arch wires are safe and innocuous ways to correct tooth irregularities. However, in a patient with poor oral hygiene, it may cause some problems. Brackets bonded on the teeth may be a retentive place for accumulation of bacterial plaque and result in caries and increase the risk of white spot lesion (WSL), which is one of the inescapable complications of fixed orthodontic treatments $[1,2]$. Clinically, WSLs are the first sign of enamel demineralization. White and opaque appearance is due to the loss of crystal structure caused by an excessive scattering of light [3].

To prevent caries and decrease the risk of WSLs, we should first disrupt the demineralization cycle. One way to prevent demineralization is reducing acidogenic bacterial plaque aggregation [4]. Streptococcus mutans, the major microorganism of the oral cavity, plays a crucial role in the demineralization process. Thus, suppressing this microorganism can lead to a lower risk of dental caries [4-6].

In the $21^{\text {st }}$ century, massive evolutions in science and technology gave rise to a new field named nanotechnology 
[7]. Nanotechnology, which is about particles at the nanoscale, takes an essential part of these advances in various fields, including orthodontics. Regarding this, the development of novel metal oxide nanomaterials brings certain privileges [8].

Among numerous metal oxides, zinc oxide $(\mathrm{ZnO})$ has extensive practical applications in the rubber industry, cosmetics, pharmaceutical production, ultraviolet (UV) laser, and electronic industry [9]. This widespread usage is due to various properties of wide-bandgap semiconductors $(3.37 \mathrm{eV})$. Furthermore, having reasonable production cost manifolds the advantages and makes $\mathrm{ZnO}$ nanoparticles (NPs) a suitable choice in different fields $[10,11]$.

Several synthesizing methods are used to produce $\mathrm{ZnO}$ NPs, such as precipitation and coprecipitation method, thermal hydrolysis techniques, solvothermal and hydrothermal processing, sol-gel method, microemulsion method, physical vapor deposition, vapor condensation method, biosynthesis method, high-energy ball milling, spray pyrolysis, vapor solid liquid, and chemical vapor deposition [12-16].

The antibacterial nature of $\mathrm{ZnO}$ NPs has been described in previous reports $[6,17-24]$. This excellent property depends on morphology, crystallinity, and size of particles [25]. ZnO NPs eliminate microorganisms through various mechanisms and show antimicrobial properties as follows: (a) reactive oxygen species (ROS) production $[26,27]$, (b) the destruction of cellular wall [28], and (c) the release of $\mathrm{Zn}^{2+}$ ions [29, 30]. ROS production by metal oxide NPs is the most reported mechanism responsible for the antimicrobial effect, which can ruin the cellular integrity including DNA, proteins, and phospholipids [27]. The size and morphology of NPs have been expressed in several studies as influential factors in their antimicrobial properties $[25,31]$. The morphology control of the ZnO NPs is one of the most critical items for their synthesis; thus, the reaction parameters should be regulated to ensure the size and shape of the product [32]. Besides, reducing friction is the reason for altering orthodontic NiTi wires' surface with these precious NPs $[17,33]$. These two factors make $\mathrm{ZnO}$-coated NiTi wires a charming alternative in modern orthodontics.

Different types of morphologies have been reported for $\mathrm{ZnO}$ NPs. The spherical, nanofiber, rod-shaped hexagonal, star-shaped, rod-shaped, and porous ball $\mathrm{ZnO}$ particles are among these NPs [34-36]. Several reports have shown different antimicrobial effects for these various morphologies [34, 37].

Overall, surface modification of $\mathrm{NiTi}$ wires with $\mathrm{ZnO}$ NPs was performed in previous studies to evaluate both antibacterial and tribologic characteristics of these NPs $[6,17]$. However, as far as the researchers investigated, no study has evaluated the morphological differences of $\mathrm{ZnO}$ NPs synthesized by different coating methods and their morphology-dependent properties. Hence, this study was aimed at coating $\mathrm{ZnO}$ NPs on orthodontic wires using five different methods and comparing their antibacterial activity due to their various microscopic morphologies.

\section{Materials and Methods}

2.1. Materials. Potassium hydroxide and ethanolamine (MEA) were obtained from Merck, Germany, and polyvinyl alcohol (PVA) (average $\mathrm{Mw}=13000-23000$ ), zinc nitrate hexahydrate $\geq 98 \%$, maleic anhydride $99 \%$, zinc acetate dihydrate $\geq 98 \%$, isopropanol $\geq 99.5 \%$, and polyvinyl pyrrolidone (PVP) (average MW = 400000) were purchased from Sigma-Aldrich, Germany.

2.2. Synthesis Methods. Commercially, round 0.016-inch orthodontic nickel-titanium (NiTi) wires (OrthoTechnology, FL, USA) were cut to $18 \mathrm{~cm}$ pieces and cleaned by ultrasound with ethanol solution for $10 \mathrm{~min}$ at $30^{\circ} \mathrm{C}$ and then immersed in a $4 \mathrm{M}$ potassium hydroxide at $100^{\circ} \mathrm{C}$ for 30 min under reflux. This makes the surface of the NiTi substrates more corrugated and results in better film adhesion.

The following techniques were used to develop different morphological ZnO NPs.

2.2.1. Chemical Precipitation Method. The wires were immersed in a solution of $0.1 \mathrm{~g}$ zinc nitrate $\left(\mathrm{Zn}\left(\mathrm{NO}_{3}\right)_{2}\right)$ in distilled water $(50 \mathrm{~mL})$, following dropwise addition of aqueous ammonia to make it alkaline under vigorous mixing condition. This makes the $\mathrm{pH}$ of the resultant solution 12 . When the solution's temperature reached $50^{\circ} \mathrm{C}$, the $\mathrm{ZnO}$ NPs were synthesized on the wires [17].

2.2.2. Chemical Vapor Deposition Method. Chemical vapor deposition (CVD) process was done by using a CVD 420 Full, double-zone electric tube furnace (Nano sat Co, Semnan, Iran). The furnace has a quartz tube with $50 \mathrm{~cm}$ length and $5 \mathrm{~cm}$ internal diameter. Using a simple CVD method, $\mathrm{ZnO}$ thin films were grown on NiTi wire substrates. Oxygen gas and high-purity metallic $\mathrm{Zn}$ powders (99.999\%) were used as oxygen and $\mathrm{Zn}$ sources, respectively. Next, at the center of the furnace, $0.3 \mathrm{~g}$ of $\mathrm{Zn}$ powder in a quartz boat was placed. At a distance of $1 \mathrm{~cm}$ from the downstream side of the source, the wires were placed horizontally. The whole system was pumped to a base pressure of about $10 \mathrm{~Pa}$ by a mechanical pump. High-purity Ar carrier gas was passed at a flow rate of $100 \mathrm{sccm}$, and oxygen gas was introduced into the reaction chamber at a flow rate of $30 \mathrm{sccm}$. The growth temperature in the reaction chamber was kept at $650^{\circ} \mathrm{C}$ for $30 \mathrm{~min}$.

2.2.3. Polymer Composite Coating. In this study, $100 \mathrm{~mL}$ aqueous polyvinyl alcohol (PVA) solution $(5 \% \mathrm{w} / \mathrm{v})$ was prepared by heating the solution at $70^{\circ} \mathrm{C}$ under constant stirring. Next, $1.5 \mathrm{~g}$ of maleic anhydride was mixed with the PVA solution using a mechanical stirrer $(1000 \mathrm{rpm})$ at $70^{\circ} \mathrm{C}$ for 2 hours. Then, $0.1 \mathrm{~g}$ of nano- $\mathrm{ZnO}$ obtained by precipitation synthesis was added to the solution while stirring. The wires were immersed into it, and polymer coating containing $\mathrm{ZnO}$ NPs was coated on the wires. The film was dried at ambient temperature and subsequently cured in the oven at $100^{\circ} \mathrm{C}$ for $90 \mathrm{~min}$.

2.2.4. Sol-Gel Method. ZnO NPs were grown by a sol-gel synthesis technique on NiTi wires. The sol was prepared by dissolving $0.22 \mathrm{~g}$ of zinc acetate dihydrate in $9.49 \mathrm{~mL}$ isopropanol. This was followed by adding $0.06 \mathrm{~mL}$ ethanolamine gradually. As the $\mathrm{Zn}$ precursor, we used zinc acetate dihydrate, and isopropanol was used as the solvent with 
ethanolamine as the stabilizer. Then, to clarify the turbid solution, it was magnetically stirred for $2 \mathrm{~h}$ at $60^{\circ} \mathrm{C}$, and the obtained solution was stored for 24 hours at room temperature. NiTi wire was dip-coated in the solution for $1 \mathrm{~min}$ and subsequently placed in the oven for $10 \mathrm{~min}$ to promote the solvent's rapid evaporation. The dip-coating process was repeated. This step was followed by drying the coated wafer at $100^{\circ} \mathrm{C}$ for $10 \mathrm{~min}$ and subsequent baking at $400^{\circ} \mathrm{C}$ for $1 \mathrm{~h}$.

2.2.5. Electrospinning Process. The electrospinning process was performed using Electroris (FNM Ltd., Iran, http://fnm ir/) as an electrospinner apparatus having a high voltage and a syringe pump controllable in range of $1-35 \mathrm{kV}$ and $0.1-100 \mathrm{~mL} / \mathrm{h}$, respectively. First, $0.38 \mathrm{~g}$ of zinc nitrate was mixed with $1.5 \mathrm{~mL}$ of distilled water, placed in an ultrasonic bath for $15 \mathrm{~min}$, and then magnetically stirred for $5 \mathrm{~h}$. The polymeric solution of PVP was prepared via mixing $1 \mathrm{~g}$ of PVP with $1.5 \mathrm{~mL}$ of ethanol and then magnetic stirring for $5 \mathrm{~h}$. Then, zinc nitrate solution was added to the PVP solution and stirred for another $5 \mathrm{~h}$. The resulting mixture was poured into a syringe and placed in the electrospinning apparatus with the NiTi wires stacked on the foil. The feeding rate of the syringe pump was set at $0.2 \mathrm{~mL} / \mathrm{h}$. The voltage of the electrospinning device was controlled at $20 \mathrm{kV}$. After $2 \mathrm{~h}$, the nanofibers were wholly placed on the wires as a coating agent. After the electrospinning process, the samples were placed in the oven for $10 \mathrm{~h}$, followed by furnace for $1 \mathrm{~h}$ at $400^{\circ} \mathrm{C}$.

2.3. Antibacterial Procedure. Round 0.016-inch orthodontic NiTi straight wires (OrthoTechnology, FL, USA) with $18 \mathrm{~cm}$ length were cleaned with $70 \%$ ethanol solution three times and divided into nine $2 \mathrm{~cm}$ pieces. The antibacterial properties of the coated wires were assessed against $S$. mutans (ATCC 35668). Bacteria were cultured under the sterile condition on brain-heart infusion (BHI) agar at $37^{\circ} \mathrm{C}$ for $24 \mathrm{~h}$. After the incubation period, the standard 0.5 McFarland concentration of bacteria containing approximately $1.5 \times 10^{8} \mathrm{CFU} / \mathrm{mL}$ was prepared into the BHI broth. Under the sterile condition, $1 \mathrm{~mL}$ of the prepared concentration was inoculated to each of the microtubes containing solution synthesis, sol-gel, electrospinning, polymer samples, and control without $\mathrm{ZnO} \mathrm{NPs}$ and incubated at $37^{\circ} \mathrm{C}$ for $24 \mathrm{~h}$. After the incubation period, approximately $20 \mu \mathrm{L}$ from all tubes was transferred to an agar medium to study the microorganisms' growth. For each tube that showed the growth, several dilutions $\left(10^{-1}, 10^{-2}, 10^{-3}\right.$, etc.) were prepared to count the number of bacterial colonies. The spread plate technique was performed to count the number of colonies in the samples. A small volume of dilute microbial suspension $(10 \mu \mathrm{L})$ was inoculated into the center of an agar plate and spread evenly over the surface with a sterile bent-glass rod and incubated at $37^{\circ} \mathrm{C}$ for $24 \mathrm{~h}$. After the incubation, the plate containing 30-300 cells was selected. Then, the number of colonies was counted and reported in CFU/mL (Figure 1).

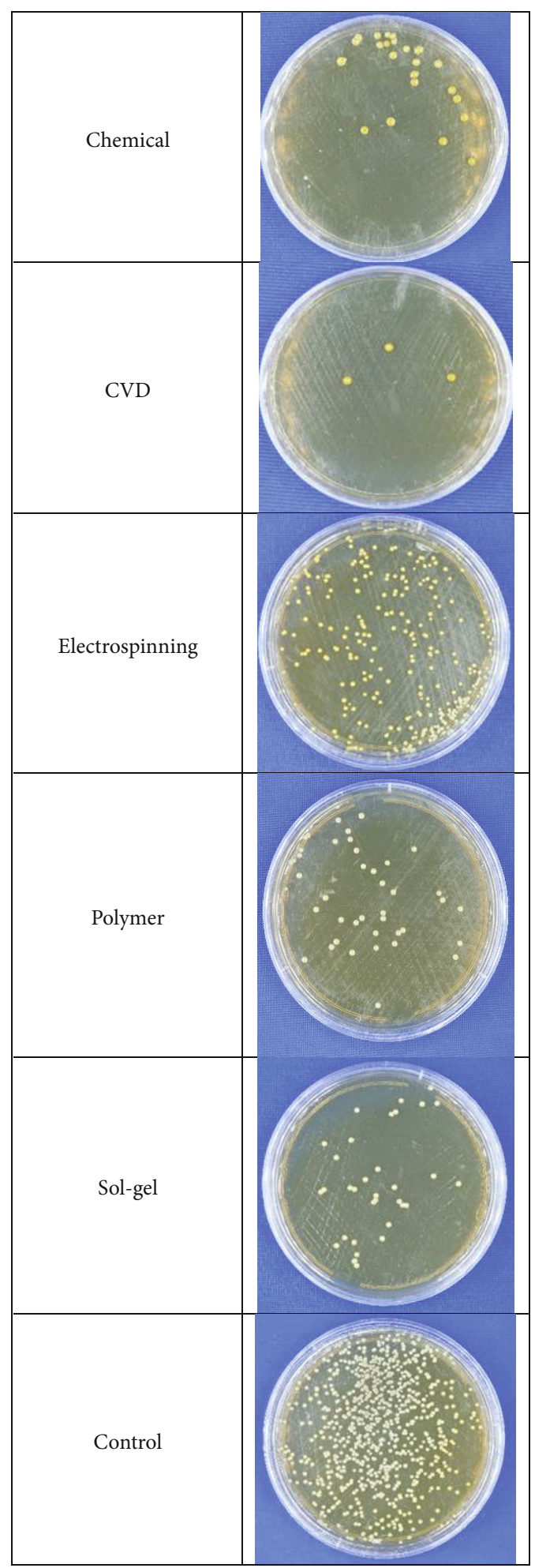

Figure 1: Colony count method.

To calculate the microbial cell reduction percentage $(R$, $\%)$, we used the following equation:

$$
R \%=\frac{\mathrm{CFU}_{\text {control }}-\mathrm{CFU}_{\text {sample }}}{\mathrm{CFU}_{\text {control }}} \times 100 \% .
$$


$\mathrm{CFU}_{\text {control }}$ and $\mathrm{CFU}_{\text {sample }}$ are the numbers of colonyforming units per milliliter for the negative control sample (without $\mathrm{ZnO}$ ) and the $\mathrm{ZnO}$ precipitation samples, respectively [25].

2.4. Characterization of NPs. To characterize the physical properties and surface morphologies of ZnO NPs, a field emission scanning electron microscope (FE SEM) (MIRA3 FEG-SEM Company: Tescan, Czech) equipped with energy-dispersive X-ray spectroscopy (EDX) was used. To identify the composition and track the formation of NPs, EDX analysis was used.

\section{Results}

3.1. Structure and Morphology. The FE SEM image in Figure 2(a) represents the morphology of ZnO NPs synthesized by the CVD technique, as it shows NPs within the range of 59-61 nm. The EDX analysis in Figure 2(b) revealed the composition of NPs as 0.14 At.\% of Zn,76.95 At.\% of O, $22.09 \mathrm{At} . \%$ of $\mathrm{Ti}$, and $0.82 \mathrm{At} . \%$ of $\mathrm{Ni}$.

Figure 3(a), marked as electrospinning technique, presents an entirely different shape of particles. Electrospinning gave a branch of fibers gathered together in a network. The length of these fibers varies from $1 \mu \mathrm{m}$ to $1.5 \mu \mathrm{m}$, and their diameter was in the range of 51-61 nm. The EDX spectrum (Figure 3(b)) confirmed the presence of $\mathrm{Zn}$ and $\mathrm{O}$ besides $\mathrm{Ni}$ and $\mathrm{Ti}$ with the At $\%$ of $3.21 \%$ and $41.39 \%$, respectively. Figure 4(a) confirms the presence of nonuniform and excursive $\mathrm{ZnO}$ NPs in nanocomposite matrices (PVA) that makes measuring the size of the particles impossible. EDX analysis shows that the At\% of $\mathrm{Zn}$ was $0.09 \%$ and that of $\mathrm{O}$ was $28.43 \%$, which was the lowest amount of $\mathrm{Zn}$ between groups and also without detection of $\mathrm{Ti}$ and $\mathrm{Ni}$. This might indicate the excellent coverage of the NiTi wire with NPs. Presence of $\mathrm{C}$ is related to the alcohol of the PVA (Figure 4(b)).

Figure 5(a) refers to the FE SEM image of ZnO NPs synthesized during the sol-gel synthesis process. Having the finest size of NPs than the previously mentioned samples with the approximate diameter of $28 \mathrm{~nm}$, spherical particles tend to cluster together. Due to the EDX spectrum, the highest At $\%$ of $\mathrm{Zn} \mathrm{(9.27 \% )} \mathrm{belongs} \mathrm{to} \mathrm{the} \mathrm{sol-gel} \mathrm{synthesis} \mathrm{process}$ (Figure 5(b)).

As shown in the FE SEM image (Figure 6(a)), well-dispersed, uniform, and hexagonal NPs with spherical ends on either side of the particle are known as precipitation synthesis [20]. The scale of the particles is in the range of 30$150 \mathrm{~nm}$, and the composition of the NPs (At\%) as seen in EDX analysis is $5.65 \%$ for $\mathrm{Zn}$ and $37.34 \%$ for $\mathrm{O}$ (Figure 6(b)).

3.2. Antibacterial Activity. A relatively high antibacterial effect was seen in all the samples containing $\mathrm{ZnO}$ NPs compared to the negative control group (without $\mathrm{ZnO}$ ) by performing the colony count method. Table 1 confirms the outcomes of the reduction in cell viability for the S. mutans. Considering the various dimensions and morphologies related to different $\mathrm{ZnO}$ particle synthesized methods, it is apparent that bacteriostatic activity results vary between the groups (Figure 7). The highest percentage of microbial cell reduction was $98.6 \%$, which belonged to the vapor deposition method with high-density NPs in a subtle and welldispersed pattern.

The precipitation method and sol-gel synthesis groups (with $96.14 \%$ and $93.05 \%$ microbial cell reduction, respectively) represented quite good antibacterial activity due to their small size and well-dispersed spherical NPs. The lowest percentage was $72 \%$, which belonged to the electrospinning group.

\section{Discussion}

$\mathrm{ZnO}$, as an antimicrobial agent, is investigated for both micro- and nanoscale. Nonetheless, the significant bactericidal effect is exhibited when the dimensions reduce in nanometer [38]. Three crystallized structures are typical for $\mathrm{ZnO}$, known as wurtzite, zinc-blende, and rock salt. In a hexagonal wurtzite structure, four oxygen atoms surround each tetrahedral $\mathrm{Zn}$ atom and make it thermodynamically stable compared to the zinc-blende structure, which is metastable in an ambient environment and needs to be stabilized by growth techniques [39].

The nonspecific manner of ZnO NPs makes it challenging to interpret the primary mechanism of antibacterial function. The proposed mechanisms may include reactive oxygen species (ROS) formation, disruption of cell wall integrity, and release of $\mathrm{Zn}^{2+}$ ions. Whatever the function is, it is obvious that $\mathrm{ZnO}$ NPs act as bacteriostatic agents. Some of the differences among these particles are due to the shape, crystallinity, particle size, and amount of $\mathrm{ZnO}$ synthesized [40].

Morphology and particle size are two significant variables that affect the antibacterial behavior of $\mathrm{ZnO}$ NPs and should be precisely controlled [40]. By improving the surface characteristics of these particles, such as biocompatibility and bioconjugation, the NPs show great characteristics, such as modifying the surface properties and high stability of NPs [41].

In this study, the antibacterial activity of ZnO NPs was significantly improved when the surface area of particles increased, by the ZnO NPs prepared via the CVD coating method [34-37]. Castro-Mayorga et al. tested the antimicrobial effects of the hexagonal-pyramid ( $\mathrm{P}-\mathrm{ZnO})$, star $(\mathrm{S}-\mathrm{ZnO})$, rod $(\mathrm{R}-\mathrm{ZnO})$, and porous ball $(\mathrm{B}-\mathrm{ZnO})$ particles synthesized via aqueous precipitation. Their results showed that the antibacterial properties of $\mathrm{ZnO}$ particles were in a direct relation with the specific surface area of particles and the hexagonalpyramid NPs (P-ZnO) had the highest surface area and antibacterial effect [34].

Stanković et al. [25] synthesized various shapes and sizes of $\mathrm{ZnO}$ NPs via different kinds of stabilizing agents, including polyvinyl pyrrolidone (PVP), polyvinyl alcohol (PVA), and poly ( $\alpha, \gamma$, -glutamic acid) (PGA) in a low-temperature hydrothermal technique. They tested the antibacterial effects of ZnO NPs against Escherichia coli and Staphylococcus aureus through the colony count method and reported a reduction in cell viability, as in the current study. The PVA group represented the highest antibacterial activity against 


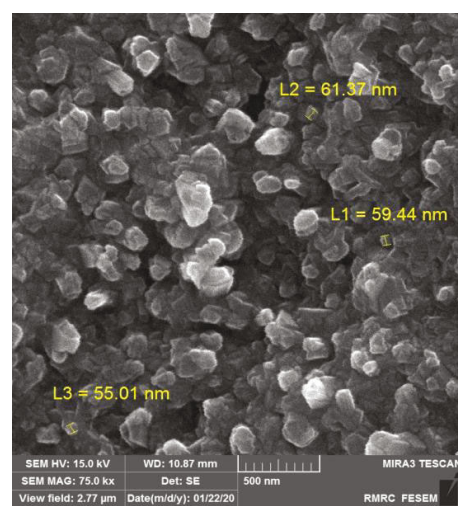

(a)

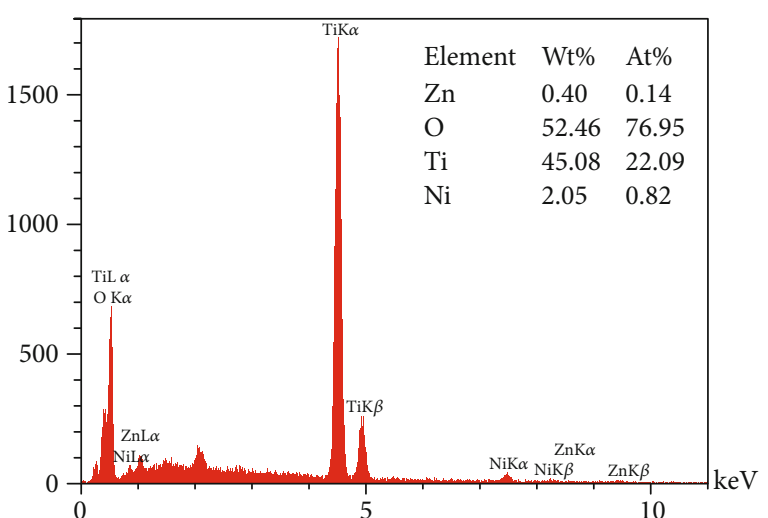

(b)

FIGURE 2: CVD method: (a) FE SEM images; (b) EDX analysis.

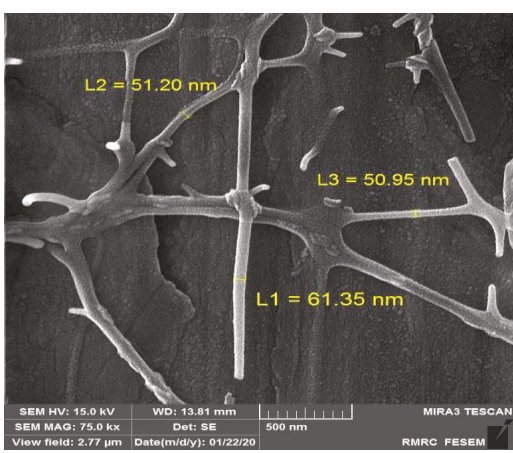

(a)

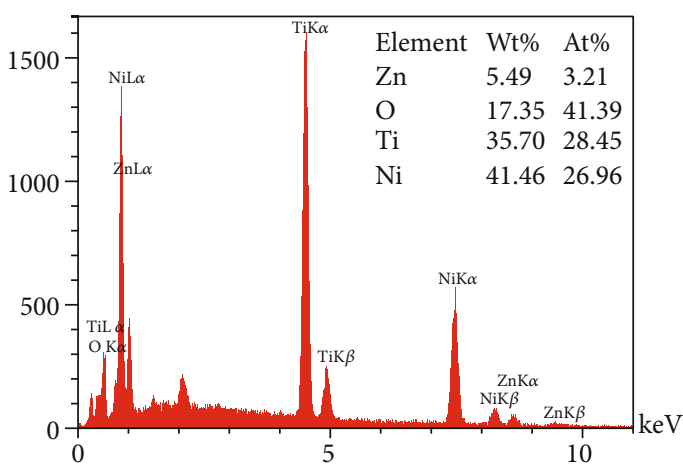

(b)

Figure 3: Electrospinning: (a) FE SEM images; (b) EDX analysis.

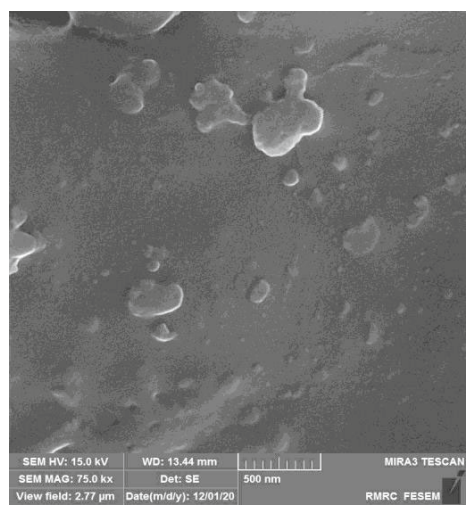

(a)

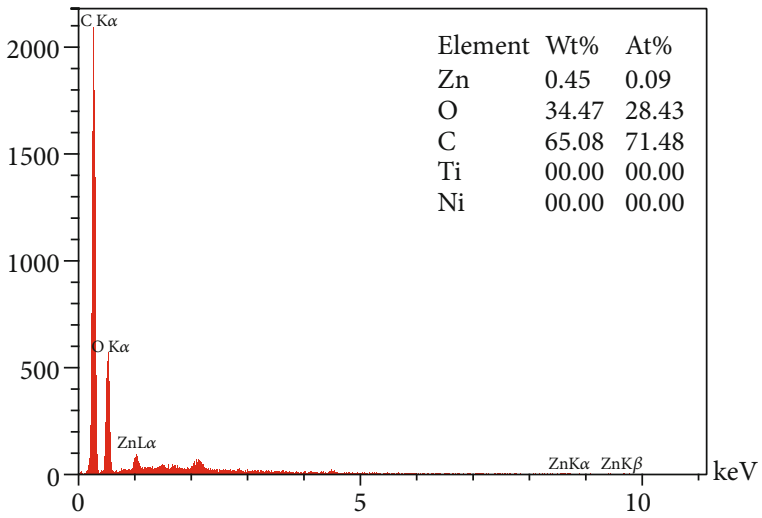

(b)

FIgURE 4: Polymer composite coating: (a) FE SEM images; (b) EDX analysis.

both microorganisms. A better reduction in cell viability of samples was shown, especially in PVA, which was similar to the current study except in the type of bacteria that was replaced with $S$. mutans, since our aim was to reduce WSLs and caries.

Talebian et al. [42] also examined the antibacterial behavior of ZnO NPs against E. coli and S. aureus via a simple solvothermal procedure without using any catalysts. In addition, they observed optical properties of the ZnO NPs by UV-vis absorption and photoluminescence. Flower-like, hexagonal rod-like, and spherical-like ZnO NPs were synthesized in water, 1-hexanol, and ethylene glycol, respectively. Due to the higher surface interstitial defects that reduce hole recombination, the flower-like NPs demonstrated excellent antibacterial behavior.

Another study conducted by Raghupathi et al. [43] evaluated the particle size-dependent antibacterial behavior of $\mathrm{ZnO}$ NPs. The results demonstrated significant antibacterial 


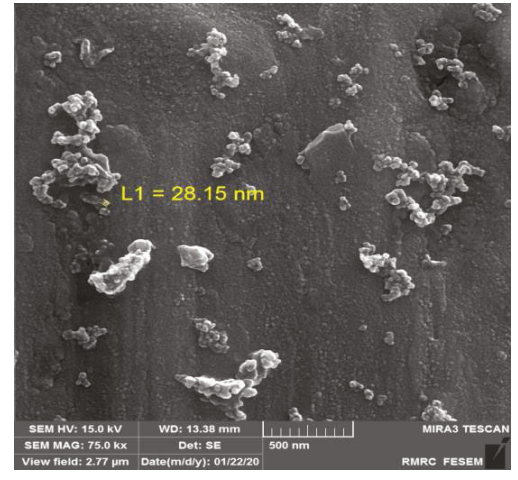

(a)

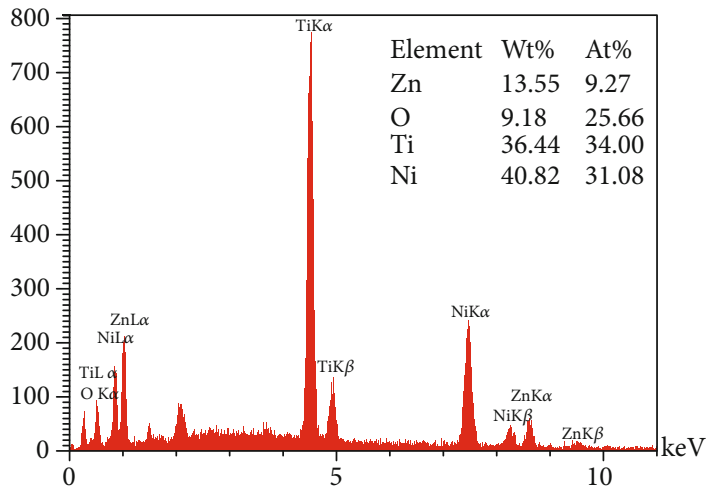

(b)

FIgURE 5: Sol-gel: (a) FE SEM images; (b) EDX analysis.

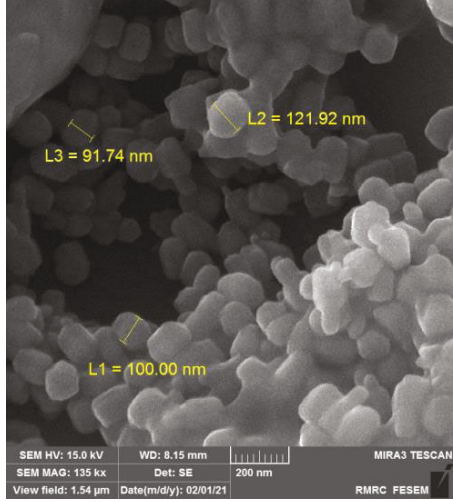

(a)

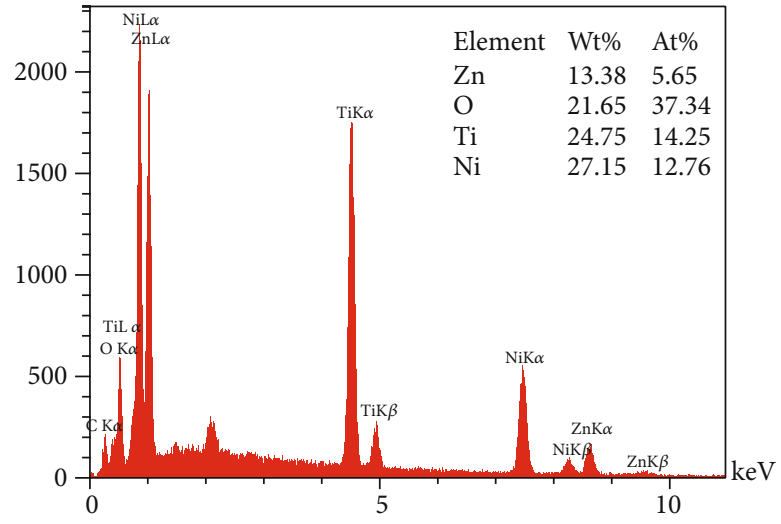

(b)

FIgure 6: Chemical precipitation method: (a) FE SEM images; (b) EDX analysis.

TABle 1: The results of antibacterial properties of $\mathrm{ZnO}$ nanoparticles on the $S$. mutans bacterial culture $(R(\%)$ reduction in viability).

\begin{tabular}{lccc}
\hline Group & Control & Number $\times 10^{8}$ & $R(\%)$ \\
\hline CVD & & $4.5(2.12)$ & $98.61(0.65)$ \\
Sol-gel & & $22.5(2.12)$ & $93.05(0.65)$ \\
Electrospinning & $324 \times 10^{8}$ & $90.5(4.95)$ & $72.07(1.53)$ \\
Chemical & & $12.5(0.71)$ & $96.14(0.22)$ \\
Polymer & & $32.5(2.12)$ & $89.97(0.65)$ \\
\hline
\end{tabular}

The results stand for mean (SD: standard deviation, $n=2$ ).

activity after decreasing particle size from $212 \mathrm{~nm}$ to $12 \mathrm{~nm}$, and particles smaller than $12 \mathrm{~nm}$ had a bactericidal function. Deteriorating the bacterial cell wall was announced as the probable reason for this cell death.

Padmavathy and Vijayaraghavan [44] used disk diffusion assay to measure the antibacterial effect of $\mathrm{ZnO}$ NPs synthesized via two different methods. The increase of inhibition zone around $\mathrm{ZnO}$ NPs against E. coli may be due to the simplified ability of smaller NPs in rupturing the bacterial membrane. All samples' concentrations above $1 \mathrm{mM}$ were bacteriostatic, and concentrations between 5 and $100 \mathrm{mM}$ were bactericidal. The bactericidal behavior was better in $12 \mathrm{~nm}$ particles compared to $45 \mathrm{~nm}$ and $2 \mu \mathrm{m}$ particles.

Dutta et al. [45] studied the antibacterial activity of $\mathrm{ZnO}$ NPs and their correlation to different particle sizes and oxygen vacancies. Their results showed more bacterial inhibition (increased bacteriostatic activity) with smaller particle sizes since decreasing the particle size could enhance the surface-to-volume ratio. In addition, $\mathrm{ZnO} \mathrm{NPs}$ with increased oxygen vacancies facilitated the interaction with a bacterial membrane containing a negative charge.

Similar to our study, Stanković et al. [25] and Talebian et al. [42] indicated the specific morphologies seen in FE SEM images close to their antibacterial activity. Larger specific surface area, small spherical and cuboid particles in sol-gel synthesis, precipitation method, and CVD can contact a greater number of $S$. mutans cells. The microbial cell reduction of $83.3 \%$ for the nanowires prepared by Wang et al. [46] with an approximate length of $1 \mu \mathrm{m}$ and a diameter of $150 \mathrm{~nm}$ is in good agreement with our nanofibers synthesized by electrospinning (with $1 \mu \mathrm{m}$ length and $61 \mathrm{~nm}$ and $72 \%$ reduction in microbial cell viability). The relatively 


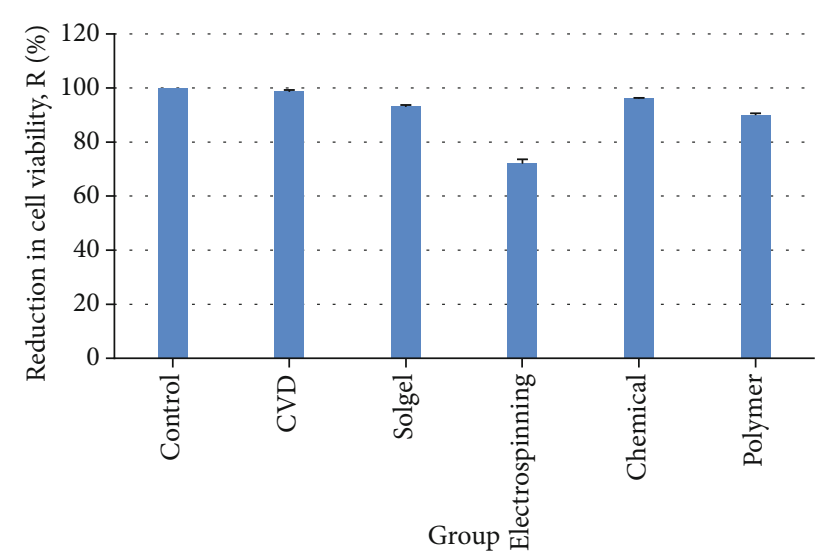

FIGURE 7: Reduction in cell viability for $S$. mutans bacteria after coating with $\mathrm{ZnO}$ particles in 5 groups.

high antibacterial activity of NPs synthesized by the sol-gel method is similar to the study directed by da Silva et al. [47] that showed high At\% of $\mathrm{Zn}(9.27 \%)$ and O (25.66\%) detected in the EDX spectrum. A close look at the EDX table reveals that low $\mathrm{At} \%$ of $\mathrm{Zn}(0.09 \%)$ in particles stabilized by PVA may be the reason for lower antibacterial activity compared to other study groups. Increasing the $\mathrm{At} \%$ of $\mathrm{ZnO}$ in polyvinyl alcohol matrices in further studies can probably enhance the bacteriocidic activity of $\mathrm{ZnO}$ NPs.

Although some previous studies attempted to show the antibacterial activity of $\mathrm{ZnO}$ NPs [25], few research has investigated the application of $\mathrm{ZnO}$ NPs in orthodontics to reduce the incidence of WSL $[6,48,49]$. In the current study, $\mathrm{ZnO}$ NPs exhibited bacteriostatic activity against $S$. mutans. Except for the study by Kachoei et al. in 2016 [17], none of the existing literature studied NiTi orthodontic wires. Similar to the current study, Kachoei et al. [17] investigated $\mathrm{ZnO}$ NPs synthesized by the chemical precipitation method; they used resazurin for antibacterial assay. The plates containing $\mathrm{ZnO}$-coated wires had no color change, indicating no bacterial growth.

Chun et al. [49] evaluated the antibacterial effect of stainless steel (SS) wires coated with titanium oxide $\left(\mathrm{TiO}_{2}\right)$ by the sol-gel method using the dilution agar plate method for S. mutans and spectrophotometry for Porphyromonas gingivalis. Coated wires showed bactericidal activity against $S$. mutans and $P$. gingivalis. Shah et al. [48] also studied the antibacterial properties of $\mathrm{TiO}_{2}$ NPs but coated on preadjusted SS brackets against Lactobacillus acidophilus instead of orthodontic wires. They used the radiofrequency (RF) magnetron sputtering method to coat the brackets. Their results indicated less bacterial mass around brackets and bactericidal effect of $\mathrm{TiO}_{2}$, which resulted in a lower rate of WSLs. Photocatalytic characteristics of $\mathrm{TiO}_{2} \mathrm{NPs}$ make them more efficient in eliminating bacteria. However, unfortunately, these catalytic properties under UV light cause serious genetic harm in human cells and tissues, so the application of $\mathrm{TiO}_{2}$-coated wires and brackets in human beings is unsuitable.

Ramazanzade et al. [6] compared the antibacterial activity of $\mathrm{CuO}-$, $\mathrm{ZnO}-$, and $\mathrm{CuO}-\mathrm{ZnO}-$ coated brackets against $S$. mutans with the colony count method. They also confirmed the bactericidal effect of NPs in all groups compared to the control group with no NPs. Also, $\mathrm{CuO}$ and $\mathrm{ZnO}-\mathrm{CuO}$ groups had better antibacterial properties than $\mathrm{ZnO}$-coated brackets on S. mutans. Even though Cu NPs have remarkable chemical, physical, and biological characteristics, their fast oxidation in front of air makes them an inappropriate choice in orthodontics.

In general, despite various studies demonstrating antimicrobial activity of NPs [40], the current study is the only one assessing the antibacterial properties of $\mathrm{ZnO}$ NPs in different $3 \mathrm{D}$ shapes and morphologies coated on NiTi wires. Interestingly, different morphologies resulted in different bacteriostatic properties based on the method used for synthesizing NPs. In addition to this attractive characteristic of $\mathrm{ZnO}$ NPs in reducing WSLs and caries during the first months of comprehensive orthodontic treatment [50], they also reduce the frictional coefficient of NiTi wires [17]. The high frictional forces while sliding the tooth for leveling and alignment of irregular teeth in the first stage of orthodontic treatment are significant disadvantages of these precious wires. NiTi wires have facilitated the clinical procedure and shortened the chair time of the first stage compared to multistrand and coaxial SS wires. Nevertheless, the overall duration of leveling and alignment stage is almost like multistrand and coaxial wires due to the frictional resistance to sliding [51]. Hence, $\mathrm{ZnO} \mathrm{NPs}$ act as solid lubricants, smoothen the surface of NiTi wires, result in decreased frictional forces, and enhance the efficacy of these orthodontic wires [17].

\section{Conclusion}

In this study, chemical precipitation method, CVD, electrospinning, polymer composite coating, and the sol-gel method produced different forms and dimensions of $\mathrm{ZnO}$ nanostructures. FE SEM images demonstrated NPs with a diameter of $60 \mathrm{~nm}$ in CVD, fiber-like forms of electrospinning reaching $1.5 \mu \mathrm{m}$ in length, hexagonal particles within a wide range of particle scale in precipitation synthesis, amorphous nanostructures in polymer composite coating, and spherical NPs with about $28 \mathrm{~nm}$ in the sol-gel method. Regardless of different physicochemical properties of $\mathrm{ZnO}$ NPs, all samples showed excellent antimicrobial results against gram-positive coccus, S. mutans. The highest antibacterial effect with $98 \%, 96 \%$, and $93 \%$ microbial cell reduction belonged to CVD, precipitation method, and sol-gel synthesis, respectively, and the lowest cell reduction was seen in the electrospinning method (72\%). The apparent antibacterial activity of smaller NPs with the larger surface area makes these methods a precious way to produce NiTi archwires to protect teeth and reduce the rate of WSLs during orthodontic treatment.

\section{Data Availability}

Data supporting the conclusion of this article are within the manuscript. 


\section{Ethical Approval}

The present study has been approved by the ethics committee of Tabriz University of Medical Sciences with the code of ethics number IR.TBZMED.VCRREC.1398.244.

\section{Conflicts of Interest}

The authors declare that they have no conflicts of interest in this research work.

\section{Authors' Contributions}

Mona Gholami and Mahdiyeh Esmaeilzadeh have contributed to this manuscript equally.

\section{Acknowledgments}

The authors would like to thank Tabriz University of Medical Sciences for supporting this project (Grant number: 63084).

\section{References}

[1] G. C. Heymann and D. Grauer, "A contemporary review of white spot lesions in orthodontics," Journal of Esthetic and Restorative Dentistry, vol. 25, no. 2, pp. 85-95, 2013.

[2] B. Angmar-Månsson and J. J. ten Bosch, "Optical methods for the detection and quantification of caries," Advances in Dental Research, vol. 1, no. 1, pp. 14-20, 1987.

[3] O. Fejerskov, B. Nyvad, and E. Kidd, Dental Caries: The Disease and Its Clinical Management, John Wiley \& Sons, 2015.

[4] M. Eshed, J. Lellouche, S. Matalon, A. Gedanken, and E. Banin, "Sonochemical coatings of $\mathrm{ZnO}$ and $\mathrm{CuO}$ nanoparticles inhibit Streptococcus mutans biofilm formation on teeth model," Langmuir, vol. 28, no. 33, pp. 12288-12295, 2012.

[5] L. Cheng, K. Zhang, M. D. Weir, M. A. S. Melo, X. Zhou, and H. H. Xu, "Nanotechnology strategies for antibacterial and remineralizing composites and adhesives to tackle dental caries," Nanomedicine, vol. 10, no. 4, pp. 627-641, 2015.

[6] B. Ramazanzadeh, A. Jahanbin, M. Yaghoubi et al., "Comparison of antibacterial effects of $\mathrm{ZnO}$ and $\mathrm{CuO}$ nanoparticles coated brackets against Streptococcus mutans," Journal of Dentistry, vol. 16, no. 3, pp. 200-205, 2015.

[7] C. Zandonella, The Tiny Toolkit, vol. 423, no. 6935, 2003Nature Publishing Group, 2003.

[8] B. Abebe, E. A. Zereffa, A. Tadesse, and H. A. Murthy, "A review on enhancing the antibacterial activity of $\mathrm{ZnO}$ : mechanisms and microscopic investigation," Nanoscale Research Letters, vol. 15, no. 1, pp. 1-19, 2020.

[9] J. Jiang, J. Pi, and J. Cai, "The advancing of zinc oxide nanoparticles for biomedical applications," Bioinorganic Chemistry and Applications, vol. 2018, Article ID 1062562, 18 pages, 2018.

[10] Ü. Özgür, Y. I. Alivov, C. Liu et al., "A comprehensive review of $\mathrm{ZnO}$ materials and devices," Journal of Applied Physics, vol. 98, no. 4, article 041301, 2005.

[11] J. Yu and X. Yu, "Hydrothermal synthesis and photocatalytic activity of zinc oxide hollow spheres," Environmental science \& technology, vol. 42, no. 13, pp. 4902-4907, 2008.
[12] B. Divband, M. Khatamian, G. K. Eslamian, and M. Darbandi, "Synthesis of $\mathrm{Ag} / \mathrm{ZnO}$ nanostructures by different methods and investigation of their photocatalytic efficiency for 4nitrophenol degradation," Applied surface science, vol. 284, pp. 80-86, 2013.

[13] M. J. Haque, M. M. Bellah, M. R. Hassan, and S. Rahman, "Synthesis of $\mathrm{ZnO}$ nanoparticles by two different methods \& comparison of their structural, antibacterial, photocatalytic and optical properties," Nano Express, vol. 1, no. 1, article 010007, 2020.

[14] M. F. Khan, A. H. Ansari, M. Hameedullah et al., "Sol-gel synthesis of thorn-like $\mathrm{ZnO}$ nanoparticles endorsing mechanical stirring effect and their antimicrobial activities: Potential role as nano- antibiotics," Scientific Reports, vol. 6, no. 1, pp. 1$12,2016$.

[15] A. Naveed Ul Haq, A. Nadhman, I. Ullah, G. Mustafa, M. Yasinzai, and I. Khan, "Synthesis approaches of zinc oxide nanoparticles: the dilemma of ecotoxicity," Journal of Nanomaterials, vol. 2017, Article ID 8510342, 14 pages, 2017.

[16] C. B. Ong, L. Y. Ng, and A. W. Mohammad, "A review of $\mathrm{ZnO}$ nanoparticles as solar photocatalysts: synthesis, mechanisms and applications," Renewable and Sustainable Energy Reviews, vol. 81, pp. 536-551, 2018.

[17] M. Kachoei, A. Nourian, B. Divband, Z. Kachoei, and S. Shirazi, "Zinc-oxide nanocoating for improvement of the antibacterial and frictional behavior of nickel-titanium alloy," Nanomedicine, vol. 11, no. 19, pp. 2511-2527, 2016.

[18] M. Kachoei, F. Eskandarinejad, B. Divband, and M. Khatamian, "The effect of zinc oxide nanoparticles deposition for friction reduction on orthodontic wires," Dental research journal, vol. 10, no. 4, pp. 499-505, 2013.

[19] M. Kachoei, B. Divband, F. Eskandarinejad, and M. Khatamian, "Deposition of $\mathrm{ZnO}$ nano particles on stainless steel orthodontic wires by chemical solution method for friction reduction propose," Research Journal Of Pharmaceutical Biological And Chemical Sciences, vol. 6, no. 3, pp. 104-112, 2015.

[20] M. Kachoei, B. Divband, F. Dabaghi Tabriz, Z. Norouzzadeh Helali, and M. Esmailzadeh, "A comparative study of antibacterial effects of mouthwashes containing $\mathrm{Ag} / \mathrm{ZnO}$ or $\mathrm{ZnO}$ nanoparticles with chlorhexidine and investigation of their cytotoxicity," Nanomedicine Journal, vol. 5, no. 2, pp. 102110, 2018.

[21] S. Jafarirad, M. Mehrabi, B. Divband, and M. Kosari-Nasab, "Biofabrication of zinc oxide nanoparticles using fruit extract of Rosa canina and their toxic potential against bacteria: A mechanistic approach," Materials Science and Engineering: $C$, vol. 59, pp. 296-302, 2016.

[22] M. Samiei, A. Torab, O. Hosseini, T. Abbasi, A. A. Abdollahi, and B. Divband, "Antibacterial effect of two nano zinc oxide gel preparations compared to calcium hydroxide and chlorhexidine mixture," Iranian endodontic journal, vol. 13, no. 3, pp. 305-311, 2018.

[23] M. Azizi-Lalabadi, L. Rafiei, B. Divband, and A. Ehsani, "Active packaging for Salmon stored at refrigerator with polypropylene nanocomposites containing $4 \mathrm{~A}$ zeolite, $\mathrm{ZnO}$ nanoparticles, and green tea extract," Food Science \& Nutrition, vol. 8, no. 12, pp. 6445-6456, 2020.

[24] M. Azizi-Lalabadi, A. Ehsani, B. Ghanbarzadeh, and B. Divband, "Polyvinyl alcohol/gelatin nanocomposite containing $\mathrm{ZnO}, \mathrm{TiO}_{2}$ or $\mathrm{ZnO} / \mathrm{TiO}_{2}$ nanoparticles doped on $4 \mathrm{~A}$ zeolite: microbial and sensory qualities of packaged white 
shrimp during refrigeration," International journal of food microbiology, vol. 312, article 108375, 2020.

[25] A. Stanković, S. Dimitrijević, and D. Uskoković, "Influence of size scale and morphology on antibacterial properties of $\mathrm{ZnO}$ powders hydrothemally synthesized using different surface stabilizing agents," Colloids and Surfaces B: Biointerfaces, vol. 102, pp. 21-28, 2013.

[26] J. Sawai, S. Shoji, H. Igarashi et al., "Hydrogen peroxide as an antibacterial factor in zinc oxide powder slurry," Journal of fermentation and bioengineering, vol. 86, no. 5, pp. 521-522, 1998.

[27] G. Applerot, J. Lellouche, N. Perkas, Y. Nitzan, A. Gedanken, and E. Banin, "ZnO nanoparticle-coated surfaces inhibit bacterial biofilm formation and increase antibiotic susceptibility," Rsc Advances, vol. 2, no. 6, pp. 2314-2321, 2012.

[28] L. Zhang, Y. Jiang, Y. Ding, M. Povey, and D. York, "Investigation into the antibacterial behaviour of suspensions of $\mathrm{ZnO}$ nanoparticles ( $\mathrm{ZnO}$ nanofluids)," Journal of Nanoparticle Research, vol. 9, no. 3, pp. 479-489, 2007.

[29] S. ATMACA, G. Kadri, and R. Cicek, "The effect of zinc on microbial growth," Turkish Journal of Medical Sciences, vol. 28, no. 6, pp. 595-598, 1998.

[30] M. Li, L. Zhu, and D. Lin, "Toxicity of $\mathrm{ZnO}$ nanoparticles to Escherichia coli: mechanism and the influence of medium components," Environmental science \& technology, vol. 45, no. 5, pp. 1977-1983, 2011.

[31] J. Tawale, K. Dey, R. Pasricha, K. Sood, and A. Srivastava, "Synthesis and characterization of $\mathrm{ZnO}$ tetrapods for optical and antibacterial applications," Thin Solid Films, vol. 519, no. 3, pp. 1244-1247, 2010.

[32] V. V. Shinde, D. S. Dalavi, S. S. Mali, C. K. Hong, J. H. Kim, and P. S. Patil, "Surfactant free microwave assisted synthesis of $\mathrm{ZnO}$ microspheres: study of their antibacterial activity," Applied surface science, vol. 307, pp. 495-502, 2014.

[33] A. Behroozian, M. Kachoei, M. Khatamian, and B. Divband, "The effect of $\mathrm{ZnO}$ nanoparticle coating on the frictionalresistance between orthodontic wires and ceramic brackets," Journal of dental research, dental clinics, dental prospects, vol. 10, no. 2, pp. 106-111, 2016.

[34] J. L. Castro-Mayorga, M. J. Fabra, A. M. Pourrahimi, R. T. Olsson, and J. M. Lagaron, "The impact of zinc oxide particle morphology as an antimicrobial and when incorporated in poly(3hydroxybutyrate-co-3-hydroxyvalerate) films for food packaging and food contact surfaces applications," Food and Bioproducts Processing, vol. 101, pp. 32-44, 2017.

[35] J. Hu, Y. Fan, Y. Pei et al., "Shape effect of $\mathrm{ZnO}$ crystals as cocatalyst in combined reforming-hydrogenolysis of glycerol," ACS Catalysis, vol. 3, no. 10, pp. 2280-2287, 2013.

[36] Y. M. Im, T. H. Oh, J. A. Nathanael, and S. S. Jang, "Effect of $\mathrm{ZnO}$ nanoparticles morphology on UV blocking of poly(vinyl alcohol)/ZnO composite nanofibers," Materials Letters, vol. 147, pp. 20-24, 2015.

[37] S. Sharma, K. Kumar, N. Thakur, S. Chauhan, and M. Chauhan, "The effect of shape and size of $\mathrm{ZnO}$ nanoparticles on their antimicrobial and photocatalytic activities: a green approach," Bulletin of Materials Science, vol. 43, no. 1, pp. 1-10, 2020.

[38] T. J. Webster and I. Seil, "Antimicrobial applications of nanotechnology: methods and literature," International Journal of Nanomedicine, vol. 7, pp. 2767-2781, 2012.
[39] A. Sirelkhatim, S. Mahmud, A. Seeni et al., "Review on zinc oxide nanoparticles: antibacterial activity and toxicity mechanism," Nano-micro letters, vol. 7, no. 3, pp. 219-242, 2015.

[40] B. Lallo da Silva, M. P. Abuçafy, E. Berbel Manaia et al., "Relationship between structure and antimicrobial activity of zinc oxide nanoparticles: an overview," International Journal of Nanomedicine, vol. 14, pp. 9395-9410, 2019.

[41] H. Otsuka, Y. Nagasaki, and K. Kataoka, "PEGylated nanoparticles for biological and pharmaceutical applications," Advanced drug delivery reviews, vol. 55, no. 3, pp. 403-419, 2003.

[42] N. Talebian, S. M. Amininezhad, and M. Doudi, "Controllable synthesis of $\mathrm{ZnO}$ nanoparticles and their morphologydependent antibacterial and optical properties," Journal of Photochemistry and Photobiology B: Biology, vol. 120, pp. 6673, 2013.

[43] K. R. Raghupathi, R. T. Koodali, and A. C. Manna, "Sizedependent bacterial growth inhibition and mechanism of antibacterial activity of zinc oxide nanoparticles," Langmuir, vol. 27, no. 7, pp. 4020-4028, 2011.

[44] N. Padmavathy and R. Vijayaraghavan, "Enhanced bioactivity of $\mathrm{ZnO}$ nanoparticles-an antimicrobial study," Science and technology of advanced materials, vol. 9, no. 3, article 035004, 2008.

[45] R. K. Dutta, P. K. Sharma, R. Bhargava, N. Kumar, and A. C. Pandey, "Differential susceptibility of Escherichia coli cells toward transition metal-doped and matrix-embedded $\mathrm{ZnO}$ nanoparticles," The Journal of Physical Chemistry B, vol. 114, no. 16, pp. 5594-5599, 2010.

[46] X. Wang, F. Yang, W. Yang, and X. Yang, "A study on the antibacterial activity of one-dimensional $\mathrm{ZnO}$ nanowire arrays: effects of the orientation and plane surface," Chemical Communications, vol. 42, no. 42, pp. 4419-4421, 2007.

[47] B. Lallo da Silva, B. L. Caetano, B. G. Chiari-Andréo, R. C. L. R. Pietro, and L. A. Chiavacci, "Increased antibacterial activity of $\mathrm{ZnO}$ nanoparticles: influence of size and surface modification," Colloids and Surfaces B: Biointerfaces, vol. 177, pp. 440-447, 2019.

[48] A. G. Shah, P. C. Shetty, C. Ramachandra, N. S. Bhat, and S. Laxmikanth, "In vitro assessment of photocatalytic titanium oxide surface modified stainless steel orthodontic brackets for antiadherent and antibacterial properties against Lactobacillus acidophilus," The Angle Orthodontist, vol. 81, no. 6, pp. 1028 1035, 2011.

[49] M.-J. Chun, E. Shim, E.-H. Kho et al., "Surface modification of orthodontic wires with photocatalytic titanium oxide for its antiadherent and antibacterial properties," The Angle Orthodontist, vol. 77, no. 3, pp. 483-488, 2007.

[50] L. Gorelick, A. M. Geiger, and A. J. Gwinnett, "Incidence of white spot formation after bonding and banding," American Journal of Orthodontics, vol. 81, no. 2, pp. 93-98, 1982.

[51] W. R. Proffit, H. W. Fields, B. Larson, and D. M. Sarver, Contemporary Orthodontics-e-Book, Elsevier Health Sciences, 2018. 